\title{
Local microcirculatory reflexes and afferent signalling in response to gastric acid challenge
}

\author{
P Holzer
}

The gastrointestinal tract is innervated by extrinsic primary afferent neurones which arise from two different sources. Spinal afferents originate in the dorsal root ganglia whereas vagal afferents have their cell bodies in the nodose ganglia. ${ }^{1}$ Most of the spinal afferents which supply the stomach and intestine of rodents contain neuropeptides such as calcitonin gene related peptide (CGRP) and the tachykinins, substance $\mathrm{P}$ and neurokinin $\mathrm{A}$ as their chemical messengers. ${ }^{2}$ In terms of modality, these neurones are to a considerable extent nociceptive afferents and are thought to serve tissue homeostasis in a dual manner. On the one hand, afferent neurones convey information to the central nervous system and thus lead to the sensations of discomfort and pain and elicit autonomic and endocrine reactions. On the other hand, peptidergic afferent neurones can release vasoactive neuropeptides from their peripheral endings and thus enhance the resistance of the tissue to injury and aid the repair of damaged tissue. ${ }^{34}$ This latter function is borne out by the abundance of CGRP and substance $\mathrm{P}$ containing axons around arterioles in the rat gastric submucosa. ${ }^{5}$

The overall aim of our studies has been to elucidate the role of afferent neurones in the vascular regulation of the stomach and in the signalling of chemical insults from the gastric mucosa to the central nervous system. Our hypothesis is that, by these two actions, chemoceptive afferent neurones make a significant contribution to homeostasis of the gastric mucosa (fig 1).

Experiments relating to the local role of afferent neurones in the gastric mucosa have shown that spinal afferents constitute an emergency system that signals for an increase in microcirculatory blood flow in the face of

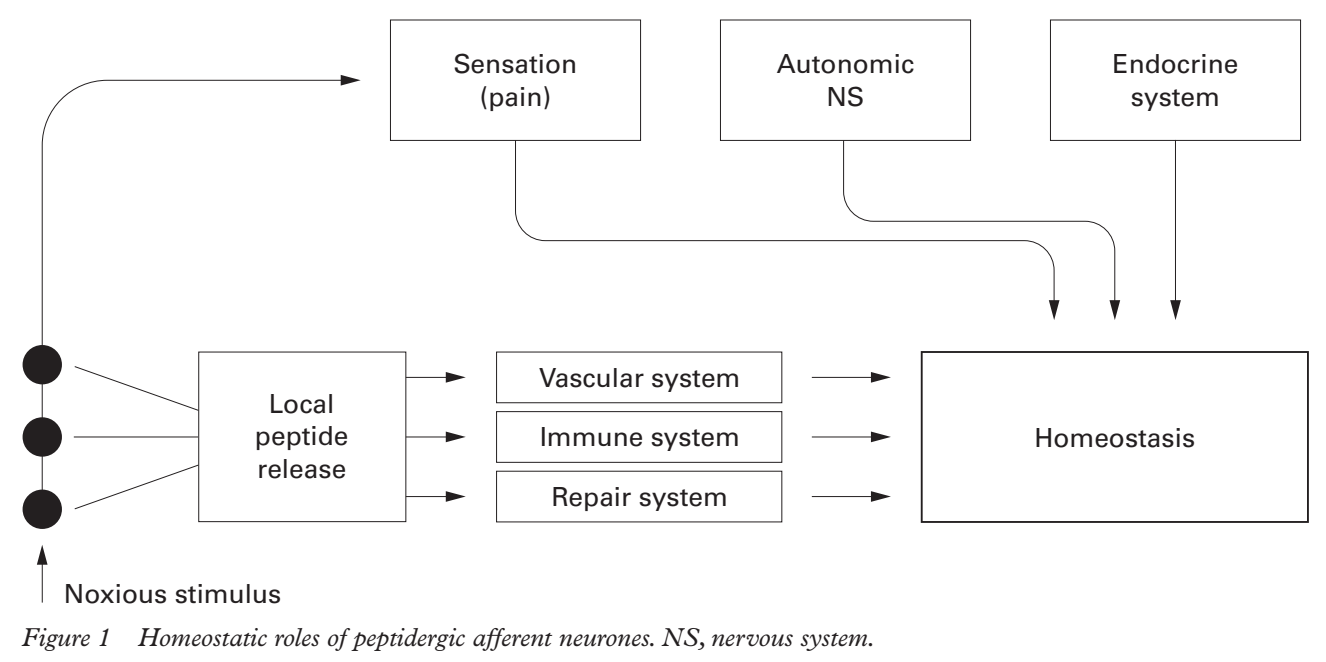

chemical injury. This function of chemoceptive afferents can be selectively manipulated and explored with the excitotoxin capsaicin (fig 2). ${ }^{6}$ Most of the homeostatic actions of capsaicin sensitive afferents are brought about by peptides released from their peripheral endings. Through these transmitters chemoceptive afferents enhance gastric blood flow ${ }^{7}$ and activate hyperaemia dependent and hyperaemia independent mechanisms of protection and repair. ${ }^{5}$ In the rodent stomach, these local regulatory roles of sensory neurones are mediated by CGRP acting via $\mathrm{CGRP}_{1}$ receptors and tachykinins acting via $\mathrm{NK}_{2}$ receptors, both peptides using nitric oxide (NO) as their common messenger. ${ }^{8-10}$ The pathophysiological potential of the neural emergency system is best portrayed by the gastric hyperaemic response to acid back diffusion, in which CGRP releasing afferents play an essential mediator role (fig 3). ${ }^{11-13}$ This mechanism limits damage to the surface of the mucosa and creates favourable conditions for rapid restitution and healing of the wounded mucosa. ${ }^{14}{ }^{15}$ Experiments involving sensory neurone stimulating doses of capsaicin have demonstrated that the same neural emergency system operates in the human gastric mucosa. ${ }^{16}$

We now pursue the question of how chemical injury to the stomach is transmitted to the central nervous system and which afferent pathways and transmitters carry this information to the brain. These studies are thought to have a bearing on the understanding and treatment of the sensory discomfort associated with functional dyspepsia, gastritis, and peptic

Abbreviations used in this paper: CGRP, calcitonin gene related peptide; NO, nitric oxide; NTS, nucleus tractus solitarii.

Department of Experimental and Clinical Pharmacology, University of Graz, Universitatsplatz 4, A-8010 Graz, Austria P Holzer

Correspondence to: Professor P Holzer. peter.holzer@kfunigraz.ac.at

Figure 1 Homeostatic roles of peptidergic afferent neurones. NS, nervous system. 

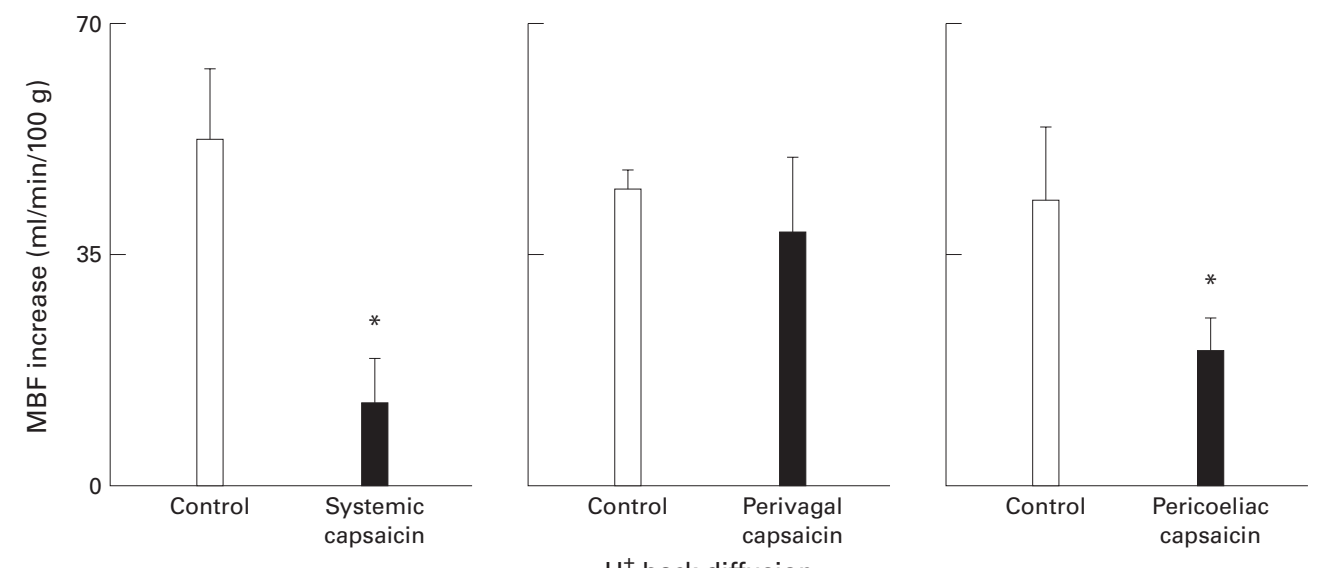

Figure 2 Influence of systemic and nerve selective treatment with capsaicin on the microcirculatory blood flow (MBF) rise due to acid back diffusion. *Significantly different from control.

ulcer. Our experimental model addresses the central signalling of a gastric mucosal acid insult, which is visualised via expression of mRNA for the immediate early gene c-fos. Induction of immediate early genes, among which c-fos is the best characterised, reflects neuronal excitation and hence can be used to map the central somata that receive primary afferent input from the periphery. In situ hybridisation autoradiography revealed that acid challenge of the gastric mucosa failed to induce expression of c-fos mRNA in the posterior thoracic spinal cord but caused a large number of neurones in the nucleus tractus solitarii (NTS) and some neurones in the area postrema to express c-fos mRNA. ${ }^{17}$ The number of c-fos mRNA positive somata in the NTS was related to the concentration of acid in the stomach but did not strictly parallel the

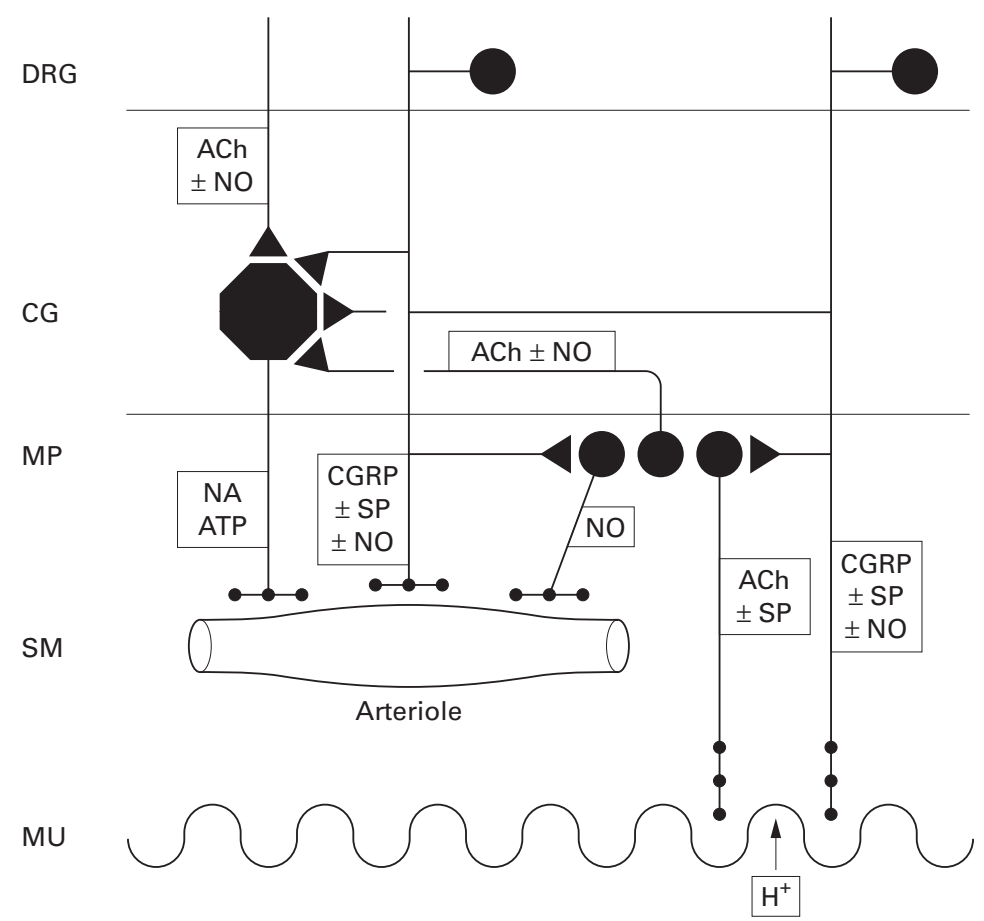

Figure 3 Neural circuitry underlying gastric hyperaemia due to acid back diffusion. CGRP, calcitonin gene related peptide; NO, nitric oxide; SP, substance $P ; N A$, noradrenaline; DRG, dorsal root ganglion; $C G$, coeliac ganglian; $M P$, myenteric plexus; SM, submucosa; $M U$, mucosa. extent of acid induced gastric mucosal damage. About $40 \%$ of the rats responded to intragastric administration of a mildly erosive concentration of $\mathrm{HCl}$ with abdominal constrictions whose time course paralleled the rapid and transient c-fos transcription in the NTS. Bilateral subdiaphragmatic vagotomy suppressed the c-fos mRNA response to intragastric $\mathrm{HCl}$ whereas pretreatment with a neurotoxic dose of capsaicin failed to alter the acid evoked expression of c-fos mRNA in the brain stem although it depleted CGRP from spinal afferents in the gastric wall. These data show that gastric acid challenge is signalled to the brain stem, but not the spinal cord, through vagal afferents that are sensitive to acid but resistant to capsaicin. ${ }^{17}$

Taken together, our observations indicate that in the rat gastric mucosa, vagal and spinal afferents subserve two different roles. Spinal CGRP releasing afferents play a local homeostatic role in the stomach as they increase tissue blood flow and thereby enhance the resistance of the gastric mucosa to acid injury (fig 4). These dorsal root ganglion afferents do not seem to carry any information about acid challenge of the normal gastric mucosa to the spinal cord. In contrast, vagal afferents, which do not appreciably contribute to the local defensive responses in the stomach, signal chemical insults from the gastric mucosa to the brain stem. Our current work is designed to study the signalling of gastric mucosal acid challenge to higher regions of the brain including the thalamus, hypothalamus, and amygdala, to elucidate the transmitters involved in the afferent processing of a chemical insult to the stomach, and to characterise the adrenoceptors and opioid receptors that could be targeted to interrupt this input from the stomach.

1 Berthoud H-R, Patterson LM, Willing AE, et al. Capsaicinresistant vagal afferent fibers in the rat gastrointestinal tract: anatomical identification and functional integrity. Brain Res 1997;746:195-206.

2 Green T, Dockray GJ. Characterisation of the peptidergic afferent innervation of the stomach in the rat, mouse, and guinea-pig. Neuroscience 1988;25:181-93.

3 Holzer P. Local effector functions of capsaicin-sensitive sensory nerve endings: involvement of tachykinins, calcitonin gene-related peptide and other neuropeptides. Neuroscience gene-related peptide

4 Vanner S, Surprenant A. Neural reflexes controlling intestinal microcirculation. Am f Physiol 1996;271:G223-30. 


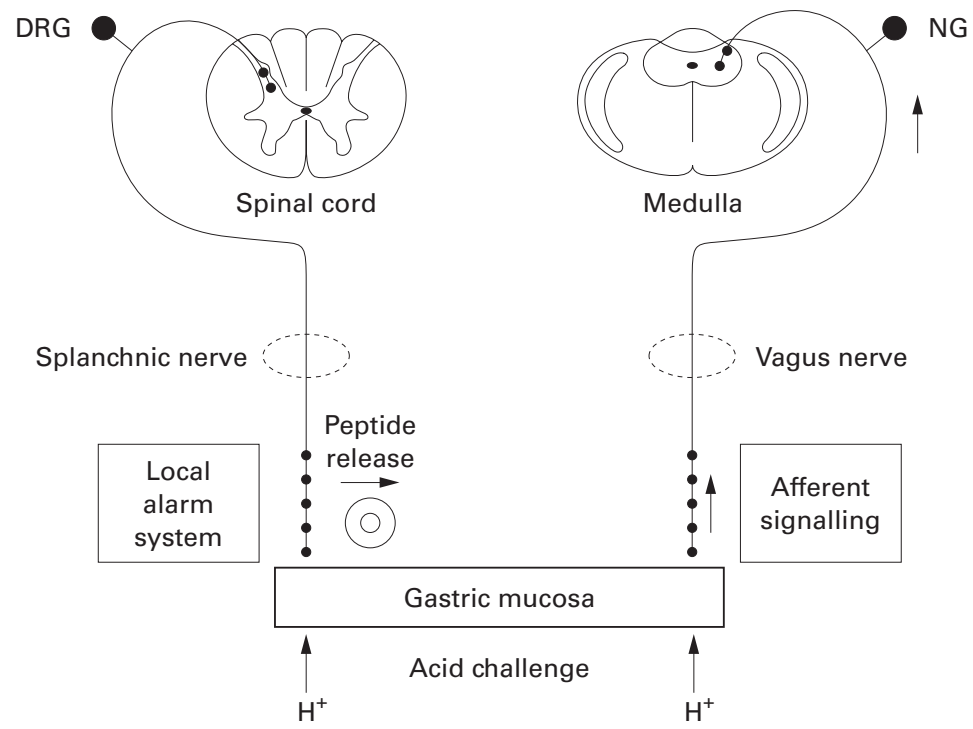

Figure 4 Functional dissociation of the dorsal root ganglion (DRG) and nodose ganglion (NG) neurones in rat stomach.

5 Holzer P. Neural emergency system in the stomach. Gastroenterology 1998;114:823-39.

6 Holzer P. Capsaicin: cellular targets, mechanisms of action, and selectivity for thin sensory neurons. Pharmacol Rev 1991;43:143-201.
7 Holzer P, Livingston EH, Sara A, et al. Sensory neurons mediate protective vasodilatation in rat gastric mucosa. Am f Physiol 1991;260:G363-70.

8 Lippe IT, Holzer P. Participation of endothelium-derived nitric oxide but not prostacyclin in the gastric mucosal hyperaemia due to acid back-diffusion. $\mathrm{Br} \mathcal{F}$ Pharmacol 1992;105:708-14.

9 Lambrecht N, Burchert M, Respondek M, et al. Role of calcitonin gene-related peptide and nitric oxide in the gastroprotective effect of capsaicin in the rat. Gastroenterology 1993;104:1371-80.

10 Stroff T, Plate 5, Seyed Ebrahim I, et al. Tachykinin-induced increase in gastric mucosal resistance: role of primary afferent neurons, CGRP, and NO. Am f Physiol 1996;271. G1017-27.

11 Holzer P, Livingston EH, Guth PH. Sensory neurons signal for an increase in rat gastric mucosal blood flow in the face of pending acid injury. Gastroenterology 1991;101:416-23.

$12 \mathrm{Li} \mathrm{D}-\mathrm{S}$, Raybould HE, Quintero B, et al. Calcitonin gene-related peptide mediates the gastric hyperemic response to acid back-diffusion. Gastroenterology 1992;102: 1124-8.

13 Manela FD, Ren J, Gao J, et al. Calcitonin gene-related peptide modulates acid-mediated regulation of somatostatin and gastrin release from rat antrum. Gastroenterology 1995; 109:701-6.

14 Allen A, Flemström G, Garner A, et al. Gastroduodenal mucosal protection. Physiol Rev 1993;73:823-57.

15 Gronbech JE, Lacy ER. Role of sensory afferent neurons in hypertonic damage and restitution of the rat gastric mucosa. Gastroenterology 1996;111:1474-83.

16 Yeoh KG, Kang JY, Yap I, et al. Chili protects against aspirin-induced gastroduodenal mucosal injury in humans. Dig Dis Sci 1995;40:580-3.

17 Schuligoi R, Jocic M, Heinemann A, et al. Gastric acid-evoked c-fos messenger RNA expression in rat brainstem is signaled by capsaicin-resistant vagal afferents. Gastroenterology 1998;115:649-60. 